\title{
MYOPIA AND COVID-19 CONFINEMENT IN MOROCCO: AN ISSUE TO BE CONSIDERED?
}

\author{
Kawtar Belkhadir ${ }^{1,2}$, Ouafae Cherkaoui ${ }^{\mathbf{1 , 2}}$
}

${ }^{1}$ Ophthalmology Unit A. Hôpital des spécialités, Rabat, Morocco.

${ }^{2}$ Mohammed $V^{\text {th }}$ University in Rabat, Morocco

\section{Corresponding Author:}

Kawtar Belkhadir, MD.

Address: Ophthalmology Unit A. Hôpital des Spécialités, Rabat, Morocco.

Email: kawta_belkhadir@hotmail.fr

Copyright $($ C) 2012- $2020 \mathrm{~K}$. Belkhadir et al. This is an open access article published under Creative Commons Attribution -Non Commercial- No Derives 4.0 International Public License (CC BY-NC-ND). This license allows others to download the articles and share them with others as long as they credit you, but they can't change them in any way or use them commercially.

DOI: $10.46327 / \mathrm{msrjg} .1 .000000000000162$ ***** published in June 19, 2020.

DOI url: https://doi.org/10.46327/msrjg.1.000000000000162

Keywords: CoVID-19; Confinement; e-learing; Morocco; myopia.

\section{Dear Editor,}

Myopia is the most common refractive disorder [1]. Its prevalence is constantly increasing, especially in East Asia where it constitutes a major public health problem [2]. Data forecasts a myopic prevalence of 5 billion people worldwide in 2050 [1, 3]. The pathophysiological mechanisms of this disorder are still not fully understood. Nevertheless, it is obvious that this disorder is secondary to genetic factors, but also behavioral, environmental and socio-cultural [1]. 1. This disorder being more and more frequent in the child and young adult, it becomes responsible for visual handicap, can be associated with school failure, and constitutes a real public health problem.
Since December 2019, a new strain of coronavirus (COVID-19) appeared in Wuhan, China, to quickly invade the world and create a major pandemic. To date, this pandemic has affected more than 7 million people, and has been responsible for over 418,000 deaths [4]. One of the strategies implemented by many countries has been the containment of the population [5]. It is estimated that 3 billion people have been affected by these measures. Children and adolescents were the first to be confined with the closure of schools and the introduction of distance education measures. In Morocco, this strict confinement lasted 3 months, and there are no plans to open schools before September 2020. 
This confinement had many consequences on the habits of children and young people: an increase in the time spent in front of television screens, computers, tablets, and smartphones, with a reduction or even a cessation of any outdoor activity depending on the socio-economic environment and the urban or rural habitation. Near vision was used much more frequently, with the use of very large and prolonged accommodation due to the use of tablets and smartphones, especially in the urban area. This could be in the context of leisure, but also to allow the maintenance of a distance education for children and adolescents, and the pursuit of home working for young adults. Indeed, the Moroccan ministry of education set up an e-learning platform for schools, high schools and faculties, making necessary the prolonged use of the screens. Some families who cannot afford a computer are forced to use smartphones to view these courses but these are even more dangerous than screens placed far from the eye such as televisions or computers. However, the significant solicitation of near vision, and conversely the lack of outdoor activity that solicits far vision are two environmental factors recognized as predisposing factors for the worsening of myopia [6]. Therefore e-learning and work from home alone have been factors increasing the time of exposure to screens and the potential worsening of refractive disorders, especially myopia. However, the American
Academy of Pediatricians recommend limiting the screen time for children aged 8 to 18 to a maximum of 2 hours a day [7]. This was incompatible with the conditions of containment imposed by the health authorities. It then becomes obvious that at least systematic breaks should be established after 2 hours of exposure of at least $30 \mathrm{~min}$ to 1 hour in order to relax the accommodation efforts.

In Morocco, during the confinement period, the ophthalmic consultation activity was limited in large parts to emergencies. So, at the end of these three months of confinement, an increase in ophthalmic consultations for refractive disorders in children, adolescents and young adults should be expected. Changes in myopia are also a very likely complication of confinement, which must be detected and treated as soon as possible, in order to stabilize this disorder and avoid its aggravation particularly in the youngest ones. It will therefore be necessary to put in place strategies to screen and educate the population at risk at the end of confinement in order to allow early and appropriate treatment of these expected visual complications. The ideal would have been to continue to follow-up the children with myopia or amblyopia even by remote consultation, because they are most likely to worsen. Now, the activity is gradually resuming, and these children have priority and are called upon to present themselves for consultation in order to allow an update on their situation. 
All authors declare no conflict of interest.

\section{REFERENCES:}

1. Wolffsohn, J. S. et al. IMI - Myopia Control Reports Overview and Introduction. Invest. Ophthalmol. Vis. Sci. 2019; 60 (3): M1M19.

2. Wen, L. et al. Objectively measured near work, outdoor exposure and myopia in children. British Journal of Ophthalmology 2020 doi:10.1136/bjophthalmol-2019315258.

3. Holden, B. A. et al. Global Prevalence of Myopia and High Myopia and Temporal Trends from 2000 through 2050. Ophthalmology 2016; 123: 1036-1042.

4. COVID-19 Map. Johns Hopkins Coronavirus Resource Center https://coronavirus.jhu.edu/map.html.
5. Souadka, A. et al. Africa Against COVID19: Can National Solidarity Complements Health System Weaknesses? -The Moroccan Experience-. Journal of Medical and Surgical Research 2020; 6 (3): 722-723 doi:10.46327/10.46327/msrjg.1.000000000 000160.

6. Lingham, G., et al. How does spending time outdoors protect against myopia? A review. British Journal of Ophthalmology 2020; 104: 593-599.

7. Council on communications and media. Children, adolescents, and the media. Pediatrics 2013; 132: 958-961. 